\title{
Martínez Estrada frente a la Crítica
}

L o primero que llama la atención al considerar el panorama crítico en torno a Martínez Estrada, es la escasez de estudios literarios inspirados en tan singular escritor. Al observar que su nómina creativa comprende unos 30 libros, que su obra fue premiada varias veces, ${ }^{1}$ y que por lo menos algunos de sus compatriotas le consideran uno de los pocos valores genuinos de la Argentina contemporánea, ${ }^{2}$ sorprende que hasta la fecha haya aparecido solamente un libro, y éste de orientación política más que literaria. En la bibliografía publicada en la revista Ciudad, en 1955, sólo figuraban unos 20 artículos sobre él; muchos de los cuales no eran más que ensayos cortos, reseñas, sueltos de la prensa diaria y notas biobliográficas. ${ }^{3}$ Aunque Martínez ha suscitado bastante interés crítico desde 1950, todavía se hace sentir la falta de un estudio sólido, extenso y bien equilibrado sobre la totalidad de su obra multiforme.

La trayectoria de la crítica martinezestradeana comprende dos etapas:

1. Martínez Estrada ganó el tercer Premio Nacional de Letras por su libro de poemas Nefelibal (1922), el primer Premio Municipal correspondiente al año 1927 por su colección de poemas Argentina; el primer Premio Nacional de Letras correspondiente al año 1929 por la colección poética Humoresca y Títires de pies ligeros; el segundo Premio Nacional de Ensayo por Radiografía de la Pampa (1933); y el primer premio del Primer Concurso Literario Hispanoamericana de la Casa de las Américas (La Habana) por su ensayo Análisis funcional de la cultura (1960).

2 Enrique Anderson Imbert ha escrito que la poesía de Martínez Estrada era "de lo mejor que dio América en su generación". Juan Carlos Ghiano opina que su obra narrativa "representa para los años inmediatos, el equivalente de lo que tue El Matadero en el periodo rosita". Borges lo consideró -en 1941- "nuestro mejor poeta contemporáneo". Ricardo Rojas una vez escribió a Martínez "acaso sea usted uno de lo más auténticamente originales de nuestros poetas". Recientemente Pablo Lejarta, en un discurso de homenaje en la Cámara de Diputados de Argentina, dijo que Martínez era "de la estirpe de Sarmiento y Marti". Otros que menciono en el presente estudio y que le han concedido un puesto de honor son Eduardo González Lanuza, Francisco López Merino y H. A. Murena

3 Véase "Acerca de E. Martínez. Estrada", bibliografía recopilada y ordenada por Héctor Grossi, Ciudad, No 1 (enero 1951), pp. 37-28. Véase también el valioso estudio y bibliografía de Martínez pot Alfredo A. Roggiano en el Diccionario de la literatura latinoamericana. Argentina $2^{\mathrm{a}}$ parte (Washington: Enión Panamericana, 1961), pp. 332-335. 
la primera, caracterizada por cierta indiferencia y falta de comprensión por parte de los críticos, y la segunda, animada por el "reconocimiento" crítico $y$, al mismo tiempo, penetrada de una actitud decididamente polémica. Podría afirmarse que la primera etapa empieza alrededor de 1927 y culmina a fines de 1949 , fecha significativa del impacto poderoso aunque algo tardío, de su obra monumental, la Muerte y transfiguración de Martin Fierro. (1948). Varios factores contribuyeron a este descubrimiento -o redescubrimiento para algunos - de Martínez Estrada. En primer lugar, el auge de Perón y el período caótico y desorientador que vino inmediatamente después de la caida del dictador produjo un rico semillero para la germinación y difusión de las ideas de nuestro autor. De igual importancia, a mi parecer, es la penetración del existencialismo de postguerra en la vida intelectual argentina. La tonalidad martínezestradeana siempre había sido más existencial que otra cosa, y ahora, con el advenimiento de la Soledad y la Nada - con mayúsculas- a estas playas, muchos, particularmente los jóvenes unversitarios de la vanguardia, se encontraban estética y filosóficamente afinados para oir el mensaje de Martínez.

De la primera etapa crítica, permanecen algunos artículos, en general lauditorios pero a veces superficiales, en revistas de limitada circulación. ${ }^{4}$ Una de las excepciones más notables a esta crítica mediocre es la magnífica reseña, escrita por el poeta López Merino, del libro de poesía, Argentina (1927). Con rara intuición observa López Merino: "... la visión panorámica y minuciosa que nos of rece Ezequiel Martínez Estrada en el presente tomo no tiene felizmente ninguna vinculación con la patria oficial, estereotipada, que nos imponen desde niños en las contratapas de los cuadernos, en los libros de lectura escolar". ${ }^{5} \mathrm{La}$ actitud de la prestigiosa revista Nosotros, representativa del "establecimiento" literario de aquel entonces, era más típica. Aunque esta revista ya había publicado algunos trabajos suyos, los editores adoptaban una postura indiferente respecto a Martínez: ni una reseña de Argentina, obra premiada por la ciudad de Buenos Aires, apareció en sus páginas. Y después de haber anunciado, en "Los premios municipales de literatura correspondientes al año 1927", que cuatro votaciones eran necesarias para que el jurado se pusiera de acuerdo, los editores se congratularon de que los ganadores eran todos "viejos amigos" de la revista. ${ }^{6}$ Cabe añadir que la misma publicación

4 En aquella época artículos sobre Martínez aparecieron en Babel (la pequeña revista bibliográfica publicada en Buenos Aires por Glusberg, no la conocida Babel de Santiago de Chile), Vida literaria, Síntesis, Don Segundo Sombra (La Plata) y La fronda. Véase las bibliografías citadas en la nota anterior.

5 Francisco López Merino, "Argentina", Síntesis, I, No 7 (dic. 1927), 114-115.

6 "Los premios municipales de literatura", Nosotros, XXII, № 227 (abril, 1928), 144-147. 
había silenciado las tres primeras colecciones poéticas de Martínez: Oro y piedra (1918), Nefelibal (1922) y Motivos del cielo (x924).7 Otra manifestación de esta actitud ocurrió a fines de 1932 cuando Martínez recibió el Primer Premio Nacional de Letras corresponiente al año 1929 por su libro de poemas Humoresca. Comentaron a la sazón los editores de la afamada revista: "Martínez Estrada es un poeta aristocrático, de escasa resonancia fuera de los círculos estrictamente literarios; y esta circunstancia ya podría motivar la cuestión de si el mayor premio nacional de literatura puede corresponder a un escritor, y con más razón a poeta, sin resonancia nacional"'. ${ }^{8}$

La recepción acordada a su primer libro de prosa, Radiografía de la pampa (1933), ensayo ahora considerado por muchos una de sus obras maestras, también ejemplifica el vacio en que se desarrollaba esta etapa crítica. No he podido encontrar reseña alguna del libro en Nosotros. Tampoco en la revista Sur, antes de octubre de 1937, fecha en que apareció el artículo devastador de Bernardo Canal Feijóo, "Radiografías fatídicas". Subrayemos que no se aducen recensiones del libro en la ya citada bibliografía compilada en 1955 por la revista Ciudad. Aunque estoy seguro de que ni mis esfuerzos bibliográficos ni los del grupo Ciudad son exhaustivos a este respecto, parece innegable que la publicación de Radiografía produjo más silencio que alboroto crítico. De una manera semejante, la reacción crítica frente a su Cabeza de Goliat (1940) fue aparentemente nula, situación curiosa, visto que el libro ha gozado de tres ediciones, a pesar de ser obra de un autor "aristocrático" y "de escasa resonancia fuera de los círculos estrictamente literarios." Es verdad que allá por los umbrales del 1941 Borges, en su Antología poética argentina, había calificado a Martínez "nuestro mejor poeta contemporáneo", 9 y que otros antologistas - Julio Noé en la Argentina y Federico de Onis en el extranjero- lo habian incluido en sus colecciones y lo habian elogiado. ${ }^{10}$ Sin embargo parece que en aquella época ni éstos ni el gran bloque de la crítica oficial habían comprendido el verdadero impacto de

7 Sin embargo, Nosotros habia publicado algunos poemas de estas colecciones. Además, las primeras obras en prosa de Martínez - tres ensayos casi olvidados hcy - fueron publicados por la misma revista. Véase "Tesoros velados", Nosotros, XI, (oct. 1917), 193-199; "El estímulo de vivir", Nosotros, XI (dic. 1917), 457-466; y "Energías anónimas", Nosotros, XII (feb. 1918), 225-233.

8 "Crónica", Nosotros, XXVI (nov. 1932), 247. Los editores de la revista eran Alfredo A. Bianchi y Roberto F. Giusti.

9 "Prólogo" a Antología poética argentina (Buenos Aires, 1941), p. 8.

10 Véase F. De Onís Antología de la poesía española e bispanoamericana 1882-1932 (Madrid, 1943), pp. 885, 1191, y Julio Noé, Antología de poesía argentina moderna (Buenos Aires, 1925), p. 344. 
Martínez Estrada, su mensaje radical y quasi-existencialista ya insinuado en su poesía y ampliamente desarrollado en la Radiografía. ${ }^{11}$

La reacción producida por la Muerte y transfiguración de Martín Fie. rro, marca, a mi juicio, el comienzo de lo que considero la segunda etapa crítica. A propósito de esto, cabe destacar que una reseña bastante extensa, firmada por Eduardo González Lanuza apareció en el No. 176 de Sur (junio de 1949). Casi por primera vez un crítico $-y$ el hecho de que González Lanuza es poeta más que crítico a secas no es mera coincidencia- ha vislumbrado las perturbadoras ideas que nutren el pensamiento martínezestradeano. Observa González que a diferencia de otros busca. dores de la argentinidad - como Mallea, Erro y Canal Feijóo- Martínez Estrada no ha aceptado un dualismo simplista entre lo superficialmente visible y malo por una parte, y por otra, lo oculto e invisible, pero esencialmente bueno. ${ }^{12}$ Según la interpretación de González Lanuza, lo que Martínez ha descubierto detrás del mal visible es sencillamente la nada, o sea la Nada con mayúscula de Kafka y los existencialistas. Aún más: González está al tanto de que esta Nada ambivalente (o dialéctica, podríamos añadir) puede interpretarse de una manera creativa, y que, por ende, "Martínez Estrada no es precisamente un nihilista, aspira, al menos, a ser todo lo contrario". ${ }^{13}$ Al terminar su reseña el citado autor sugiere que Martínez, con toda probabilidad, habría llegado a las mismas conclusiones respecto a lo esencialmente humano si en lugar de haber seleccionado al argentinísimo Martín Fierro para su análisis, hubiera escogido a cualquier gran figura de la literatura alemana, rusa - española. Algunos, quizá, creyendo que Martínez ha traspasado los límites de su estudio, pondrán objecciones a este universalismo. A tales objecciones replicaría González con esta aguda observación: "No estoy muy seguro de que esta gravísima objeción no constituya el mérito más firme del libro". ${ }^{14}$ Otros también elogiaton el libro, aunque con menos comprensión y con más reservas: nótese, por ejemplo, la reseña de Dardo Cúneo que apareció casi simultáneamente en la revista Cuadernos Ame-

11 Estudio las relaciones temáticas entre la poesía y prosa de Martínez en mi ponencia "Martínez Estrada: The Formative Writings" presentada en la Modern Language Association of America (Chicago, dic. 1965). El texto de esta ponencia apareció en la revista Hispania. XLIX (marzo, 1.966), 54-60.

${ }_{12} \mathrm{H}$. A. Murena ha subrayado este punto recientemente en su artículo "Carta de Río de la Plata", Asomante, XX (enero-mayo 1964), 72-76. Dice que la fórmula "argentina visible" versus "argentina invisible" de Mallea "no resultaba apta para esclarecer del todo esos pliegues del carácter nacional que son fuente de muchos males comunes".

13 "Muerte y transfiguración de Martín Fierto", Sur, No 176 (junio 1949), página 66.

14 Ibid., p. 70. 
ricanos. ${ }^{15}$ El análisis de la obra martínezestradeana presentado por Alberto Zum Felde en su Indice crítico de la literatura bispanoamericana, publicado en 1954 pero necesariamente compilado algún tiempo antes, está basado principalmente en la Muerte y transfiguración y en la Radiografía. En su valiosísimo estudio Zum Felde enfoca estos ensayos de una manera lúcida y compacta. ${ }^{16}$ Sin embargo el crítico uruguayo carece de una cierta dosis de empatía requerida para ver las consecuencias extremas del pensamiento de Martínez. Su posición, por tanto, no corresponde precisamente a la primera etapa crítica, aunque tampoco sería lícito decir que es típica de la segunda.

El comentarista que ha interpretado a Martínez Estrada con la mayor compenetración y claridad es, sin duda, H. A. Murena. Su ensayo, "La lección de los desposeidos", publicado en Sur (octubre de 1951) e incluido en su libro de 1958, El pecalo original de América, es imprescindible para el que quiera comprender no sólo las ideas básicas de Martínez Estrada, sino también su poderosa influencia entre la juventud intelectual argentina de las épocas pre-peronista y peronista. Sería difícil emprender aquí un análisis minucioso de las relaciones idealógicas entre Martínez y esta generación. Además, esta tarea ya ha sido realizada, en parte, por Emir Rodríguez Monegal en el primer ensayo de su interesante libro, El juicio de los parricidas: La nueva generación argentina $y$ sus maestros (1956).

Mientras Murena y otros escritores jóvenes - tales como los hermanos Viñas y Rodolfo Kusch que trabajaban en torno a las revistas Ciudad y Contorno - aceptaban, aunque con reservas y matices personales, el mundo ideológico de Martínez, ${ }^{17}$ otros le estaban dirigiendo un ataque en gran escala. En 1954 aparece el librito Crisis y resurrección de la literatura argentina por Abelardo Ramos, rara combinación de peronista, marxista heterodoxo, y jingoísta ramplón. Ramos, en una diatriba que Rodríguez Monegal ha llamado - y con razón- "crítica de mala fe", staca a Martínez Estrada por su "desfiguración" de Martín Fierro, por su

15 "Martínez Estrada, Martín Fierro y la Argentina", Cuadernos Americanos, XLVI, No 4 (jul-ag. 1949), 210-217.

16 Véase Índice crítico de la literatura bispanoamericana: El ensayo y la críttca (México, 1954), pp. 472-80.

17 Algunos artículos de interés especial en estas revistas son: Ismael Viñas, "Reflexión sobre Martínez Estrada", Contorno, No 4 (dic. 1954) pp. 2-5; Rocolfo Kusch, "Lo superficial y lo profundo en Martínez Estrada", Contorno, No 4 (dic, 1954), pp. 5-8; David Viñas, "La historia excluida: Ubicación de Martínez Estrada", Contonno, No 4 (dic. 1954) pp. 10-16; Adelaida Gigli, "La poesía de Martínez Estrada: Oro y piedra para siempre", Contomo, No 4 (dic. 1954), Fp. 17-19; Rodolfo A. Borello, "Dos aspectos esenciales de la radiografía de la pampa", Ciudad, No 1 (enero, 1955), pp. 24-27; e Ismael Viñas "Alrededor del Sarmiento", Ciudad, No 1 (enero 1955), pp. 30-38. 
elogio de escritores extranjeros (Guillermo Enrique Hudson, por ejemplo), y por varias otras transgresiones literarias. ${ }^{18}$ Como observa Rodríguez Monegal, el libro de Ramos no es digno de una réplica seria. El libro de Fermin Chávez, Civilización y barbarie: El liberalismo y el mayismo en la historia y cultura argentinas (1956), es algo semejante en cuanto a la falta de comprensión de nuestro autor, aunque la orientación de este estudio es más literaria que política. En el capítulo dedicado a Martínez, "El Martín Fierro y las mistificaciones de Martínez Estrada", Chávez peca principalmente por su inhabilidad de compenetrar la función de lo ambivalente, o sea la riqueza dialéctica en Martínez, tema bastante enmarañado que desarrollo en otra parte. ${ }^{19}$

El aspecto político del pensamiento martínezestradeano, implicitamente expresado en varios escritos suyos publicados antes de 1956, se torna explícito en dos obras de invectiva violenta: ¿Qué es esto? (1956) y Exbortaciones (1957). Era de esperar que estos libros produjeran una fuerte reacción, dado que en ellos atacó a los peronistas englobando también' a los que gobernaban el país después de la dictadura. En efecto, Martínez dio rienda suelta a su anarquismo radical, a su impaciencia con las masas engañadas y autoengañadas, a su odio intenso hacia $\mathrm{el}$ estado moderno y hacia los políticos profesionales. El contraataque surgió casi inmediatamente. Agustín Ferraris, defensor del "despertar profundamente democrático que significó para el país el fenómeno peronista", le tilda de "aristocratizante", "resentido", "ilógico" y "contradictorio". ${ }^{20}$ Para Ferraris lo más irritante y desconcertante es que "Todo lo malo que Martínez ha dicho en el comienzo del peronismo, lo repite, casi con la misma inferiorizada forma. . . de los antiperonistas" ${ }^{21}$ Opinión que revela una falta básica de percepción por parte de Ferraris. Como muchos otros concibe el mundo político en términos tajantes de blanco o negro, "los nuestros" y "los otros". Además, insiste en que todos se pongan fiel e íntegramente de un lado o de otro, simplificación de la realidad rotundamente rechazada por hombres del talante de Martínez Estrada.

El estudio de J. J. Sebreli, Marínez Estrada: Una rebelión inuitil (1960), tiene mucho mérito a pesar del punto de partida político del autor. Es, además, el único libro completo dedicado a Martínez. Sebreli no

\footnotetext{
18 Véase los capítulos "Ni crítica ni literatura", pp. 25-27; "Muerte y transfiguración del Martín Fierro", pp. 27-30; "Un escritor de lengua inglesa, gran escritor argentino?", pp. 30-40; y "La politica como historia", pp. 41-48 en Crisis y resurrección de la literatura argentina, 2a edición (Buenos Aires, 1961). 19 Véase nota 11.

20 Pido la palabra: respondiendo a Ezequiel Martinez Estrada, Mario Amadeo * Ernesto Sábato (Buenos Aires, 1957), pp. 86 y ss.

21. Ibid., p. 87.
} 
se ha limitado a lo político. Analiza las fuentes intelectuales de nuestro autor, la temática básica de su prosa y señala las ricas ambivalencias en su obra: el pesimismo telúrico contra la naturaleza paradisíaca; el determinismo contra la libertad; y el valor individual contra las incursiones del estado moderno, además de múltiples matizaciones. Lo que no consigue es apresar la manera en que Martínez se ha aprovechado de estas contradicciones aparentes para formular una visión más rica de la realidad, juego dialéctico que nos hace pensar en otro gran manipulador de contradicciones y paradojas, Miguel de Unamuno. Sebreli, izquierdista militante y exdiscípulo confeso de Martínez, rechaza esta manera de pensar y califica a su antiguo maestro de "irracional" y "escéptico". El hecho que precipita una reacción más vigorosa es que este escepticismo y nihilismo producen "una actitud puramente teórica, contemplativa, quietista, reacia a todo cambio violento". ${ }^{22}$ Palabras curiosas al tener en cuenta que en el mismo 1960 Martínez visitó Cuba e inició su íntima asociación con la vida intelectual de la isla revolucionaria. Esta asociación dio el fruto poco contemplativo y quietista de obras propagandísticas como el violento Verdadero cuento del Tio Sam (1963). El libro de Sebreli Martinez Estrada: Una rebelión inuitil es un estudio muy informativo y de bastante compenetración a pesar del tono polémico y de los prejuicios del autor. Sebreli no tiene miedo de habérselas con las ideas más complejas de Martínez, y por eso hay que respetar sus esfuerzos.

Martínez Estrada vivió en el extranjero durante la mayor parte del último lustro de su vida, y como consecuencia, su perfil de pensador se va desvaneciendo de la actualidad de su patria. Sin embargo, es difícil explicar el silencio relativo en torno a Martínez sólo a causa de su ausencia. Cuando regresó a su patria se consideró "un ídolo en desgracia,", ${ }^{23}$ y según Murena "se sumió en un silencio total". ${ }^{24}$ Su muerte, en noviembre de 1964, no ha producido gran alboroto en los círculos literarios, aunque hace poco la revista Sur le ha dedicado un penetrante estudio valorativo firmado por Aldo Prior. ${ }^{25}$

22 Martinez Estrada: Una rebelión inutil (Buenos Aires, 1960), pp. 86.

23 Citado por T. David Danielson en su nota "Death of a Master", Hispania, XIVII (May. 1965), 352. La referencia original es de la revista argentina Pr . mera plana, 4 de agosto de 1964.

24 "Carta de Río de la Plata", Asomate, XX (ene--mayo 1964), pp. 76.

25 "Después de Martínez Estrada", Sur, No 293 (marzo-abril 1965), 32-43. Véase también el caluroso homenaje publicado en México "Escritores y amigos teruerdan a don Ezequiel Martínez Estrada", La Gaceta: publicación del Fondo de Cultura Económica, XI, No 124 (dic. 1964). Por último, cabe mencionar que ha aparecido, en el número 295 de la revista Sur (julio-agosto de 1965), un homenaje digno de nuestro autor. Desgraciadamente este número de Sur llegó a nuestras manos demasiado tarde para ser considerado en el presente estudio. 
Antes de concluir este breve esbozo de la relación entre Martínez Estrada y la crítica, cabe haccrnos una pregunta básica, ¿al fin y al cabo qué valor tiene Martínez para los argentinos del siglo $\mathrm{xx}$, particularmente para los intelectuales? H. A. Murena nos of rece una respuesta elocuente. Para mejor apreciar el homenaje of recido por Murena, hay que citar la descripción que este escritor ha hecho del ambiente intelectual argentino a fines de los 30: "Se respiraba un aire muerto y estancado, y cuando imaginábamos que esa podría ser la atmósfera definitiva, una paralizante angustia nos atacaba". ${ }^{26}$ Pero el descubrimiento de Martínez Estrada, afirma Murena, provocó un verdadero renacimiento espiritual: "[Martínez Estrada] utilizó el virus, la podre, para vacunar, para sanar. . Ello explica que haya un abismo entre Martínez Estrada y las obras anteriores a él... [Sarmiento, Alberdi, Martí, Echeverría, Ingenieros] eran hombres que acertaban con la verdad una vez por semana, un poco por azar, mientras Martínez Estrada tiene la verdad a cada minuto, sin parar. .."27

Físicamente débil, sin hijos, poseido de un anhelo vago y frustrado por un paraíso perdido, confinado durante muchos años de la vida a un puesto rutinario en el correo, Martínez ha sido desde hace tres décadas un fantasma literario en su propio país. Menos conocido que sus compatriotas Borges y Mallea, y seguramente mucho menos comprendido, Martínez Estrada pasó su vida lejos del gran mundo de "movimientos", de manfiestos y grupos literarios. Más bien cultivó la lealtåd intensa, el amor profundo de la naturaleza, y sobre todo, el fino arte del fracaso. Como el "argentino invisible" malleano - a quien se parecía bastanteha sido una presencia más que una realidad visible.

University of Missouri

MAR'TIN S. STABB

Columbia, Missouri

$26 \mathrm{El}$ pecado original de América (Buenos Aires, 1958), p. 113.

27 Ibid., p. 123. 